\title{
APPROXIMATING CULTURAL RESPONSIVENESS: TEACHER READINESS FOR ACCOMMODATIVE, BIOGRAPHY-DRIVEN INSTRUCTION ${ }^{1}$
}

\author{
Kevin G. Murry ${ }^{2}$ \\ Kansas State University, USA \\ Melissa Holmes \\ Kansas State University, USA \\ Shabina Kavimandan \\ Kansas State University, USA
}

\begin{abstract}
Although many educators espouse tenets of culturally responsive teaching praxis (CRTP) they struggle to effectively apply it in classrooms. Some teachers are unsure how to address the multifaceted assets and needs of students from various races, ethnicities, and home countries. Other teachers operate from a deficit perspective that emphasizes perceived gaps in knowledge or skills among such learners, with little regard for their prior knowledge, experiences, or ways of knowing (assets). Responding to the needs of both kinds of teachers, Herrera (2010, 2016) developed Biography-Driven Instruction (BDI), a social constructivist method of CRTP that supports educators in making the curriculum accessible, relevant, and rigorous. This phenomenological research investigated teachers' perspectives on BDI use in situ and found both: (a) approximations of mutual accommodation in CRTP and (b) five themes indicative of participant voice regarding BDI effectiveness amidst complex facets of student diversity. Implications for teachers and teacher educators are explicated.
\end{abstract}

Keywords: culturally relevant education; educational methods; instructional strategies; professional development; capacity building

\footnotetext{
${ }^{1}$ A PowerPoint synthesis of selected findings related to this research was presented at the annual meeting of the American Educational Research Association (AERA), April 5-9, 2019, Toronto, Ontario, Canada.

${ }^{2}$ Correspondence: Department of Curriculum and Instruction, College of Education, Kansas State University, 219 Bluemont Hall, 1104 Midcampus Dr., Manhattan, KS, 66506-2131; Email: xmas@ksu.edu
} 


\section{Introduction}

Cultural and linguistic diversity have been and will continue to be hallmarks of American classrooms for the foreseeable future. Radical increases in the racial, ethnic, cultural, and linguistic diversity of these classrooms became noteworthy in the 1990s and continue today (Hammond, 2015; National Center for Education Statistics (NCES), 2016). For example, NCES (2016) has reported that the percentage of school-age children who were White decreased from 62 percent in 2000 to 53 percent in 2013. Concomitantly, the percentage who were Black decreased from 15 to 14 percent. On the other hand, the percentage of children who were from other racial/ethnic groups increased during this period. The percentage who were Hispanic increased from 16 to 24 percent and those who were Asian, from three to five percent. Meanwhile, the percentage for those who were of two or more races increased from two to four percent. Similar increases were evident in the population of emergent bilingual, sometimes referred to as English Language Learning (ELL) students, in U.S. schools. For instance, the percentages of Hispanic (29 percent), Asian (20 percent), and Pacific Islander (14 percent) students participating in programs for these emergent bilinguals were higher than the total percentage in 2013 (NCES, 2016).

Notwithstanding these demographics and associated trends toward more culturally and linguistically diverse (CLD) classrooms, the current teaching population in K-12 schools is not indicative of them. In fact, NCES (2017) reports that people of color represent 51 percent of public-school students, while White teachers control 83 percent of their classrooms. In addition, many of these White teachers continue, despite decades of social activism and change, to hold deficit perceptions about students from other races, cultures, and ethnicities (Herrera, Murry, Kavimandan, \& Holmes, in press; Keefer, 2017; Lew \& Nelson, 2016; Vázquez-Montilla, Just, \& Triscari, 2014; Young, 2010).

These deficit perceptions are fundamentally grounded in a technocratic perspective on schooling and teaching (Crego-Emley and Treuhaft-Ali, 2017; Gorski, 2014; Mehta, 2013). In turn, this top-down, business-like view holds that the public education system is best equipped for efficiency. Accordingly, its function is to efficiently graduate the highest percentage of candidates, who also happen to be those who are best prepared (i.e., bring the lowest compensatory cost) for current, system design. Accordingly, those students who arrive with biographies that don't match the expectations of the technocratic system are not unlike suppliers who bring inadequate or nonstandard materials to the job of building readiness for graduation.

Technocratically speaking, they complicate efficiency by holding inordinate expectations that the system is designed to address these irregularities (i.e., versus its superordinate goal of efficiency). Hence, the technocratic perspective argues that students with deficits (and/or nonstandard challenges) should be remediated (or prepared in auxiliary programs/locations) prior to full entry into the efficient, educational system.

Not surprisingly, this view of education ultimately holds, not the system, but the CLD student (and/or his/her family) accountable for any failures to perform at the formative level or graduate at the normative one, since their biographies were exceptions (deficient) to the expected inputs necessary for the efficient operation of the system. Keefer (2017) argues that these technocratically-focused perspectives and structures have, for decades, persistently shaped educational policy at multiple levels. Crego-Emley and Treuhaft-Ali (2017) further assert that arbitrarily established accountability schemas have exacerbated persistent racial inequalities, as manifested through technocratic responses to subpar performance via punitive

discipline and high dropout rates. Recent research indicates that deficit-laden biases and beliefs, often driven by the technocratic perspective, untowardly and persistently influence 
teachers' pedagogy with students whose race, culture, or first language may differ from that of the teacher or the expectations of the system (Herrera et al., in press; Keefer, 2017; Lew \& Nelson, 2016; Vázquez-Montilla, Just, \& Triscari, 2014).

\section{Asset-Based Perspectives on Teaching and Learning}

The trend toward culturally responsive teaching praxis (CRTP) has, in part, been an emergent and evolving response to: (a) changing student demographics, (b) comparatively unchanging teacher demographics, (c) the persistence of technocratically-sustained, deficit perceptions among teachers who are not cross-culturally proficient, and (d) the immutability of low and technocratically tolerated, academic achievement among students of color (CregoEmley \& Treuhaft-Ali, 2017; Herrera et al., in press; Keefer, 2017; Lew \& Nelson, 2016; Vázquez-Montilla et al., 2014).

Gay (2010) defined CRTP "as using the cultural knowledge, prior experiences, frames of reference, and performance styles of ethnically diverse students to make learning encounters more relevant to and effective for them" (p. 31). CRTP is a more student-centered, bottom-up perspective on appropriate practices for CLD students and rests on six dimensions:: (1) holding high expectations, (2) engaging students' knowledge systems and experiences, (3) bridging home-school gaps, (4) educating the whole child, (5) using student strengths to drive instruction, and (6) liberating students from oppressive educational practices.

Today, effectively delivered CRTP actualizes longstanding, thoughtful, purposive, and advocative efforts to move teachers and teaching away from deficit perceptions about CLD students toward more comprehensive understandings of difference, culture, accommodation, differentiation, and teaching. Through such efforts and associated frameworks, difference is approached as reality, culture is abstracted as asset (e.g., knowledge, ways of knowing, differential lens), and teaching amidst diversity is reconceptualized as facilitated maximization of students' assets in ways that are meaningful, purposeful, liberating, and enabling.

Yet, culturally responsive education remains variously misconceived, misapplied, underutilized, and/or inconsistently understood by both scholars and practitioners. For example, one meta-analysis of 45 classroom-based studies from 1995-2008 found that less than one third of classroom teachers utilized CRTP effectively (Morrison, Robbins, \& Rose, 2008). Most studies of CRTP to date have been case studies, ethnographies, or descriptive research that have rarely entailed participant observation or action research methodologies (Keefer, 2017; Young, 2010). Further, Hammond (2015) asserts that CRTP is variously: (a) confused with multicultural education by K-12 teachers, (b) conceptualized as a script that must begin with teachers' self-examination of their own implicit biases, and (c) misconceived as a socioemotional learning program to build students' self-esteem.

Fundamentally, we assert that this theory-into-practice gap in most forms of K-12, CRTP arises from a lack of relevance. For today's teachers, what's relevant is often what aligns with their school district's latest emphasis in professional development (PD) or protocols for acceptable, classroom practice. Tragically, their alternative potentials and agencies as professionals are too often disregarded or threatened by: (a) technocracy-driven, highly scripted, protocols for curricula, instruction, and assessment, (b) delimited autonomy to deviate from script or generate focal protocols for classroom realities, and/or (c) rigid accountability for student performance on highly standardized, norm-referenced tests. Although these technocratic emphases are often esoterically derived, authoritatively implemented in-house and on video, and frequently change from year to year -- haggard 
strategies for use in isolation with CLD students tend to prove a common thread across modish architypes and emphases.

What's relevant to CLD students, on the other hand, is often a product of a constellation of related influences, the most salient of which are: (a) socialization patterns and emphases in their home culture; (b) lived experiences with challenges of race, language differences, academic expectations, and poverty; (c) foci and activities that enable the occasional but infrequent escape from the trials and ordeals of being different, learning in unfamiliar ways, acquiring a second language, adjusting to a new and different culture, and attempting to academically perform effectively in a second language.

\section{Theoretical Framework, Part I: Biography-Driven Instruction}

The Biography-Driven Instructional (BDI) method for CLD and other students was intentionally designed to address both of these formidable challenges of relevance for teachers and their students (Herrera, 2016). BDI guides teachers to maximize four interrelated facets of the student biography, including the sociocultural, linguistic, cognitive, and academic (Herrera, 2016; Herrera \& Murry, 2016), in the effective, yet humanistic education of CLD and other students. These facets are situated within the context of the learner's biopsychosocial history, which encompasses biological, psychological, and sociological factors that influence - and are continually influenced by - the teaching and learning dynamics in the classroom (Herrera, 2016).

For teachers, purposively designed instructional strategies that align with our field's state of knowledge about what motivates, engages, educates, and advances and sustains students' progressive trajectories are part and parcel of the BDI method (addresses dimension \#1 of Gay's (2010) six dimensions for CRTP). BDI strategies are differentiated combinations of contextual and situational processes and actions that involve both teachers and students. This design facilitates opportunities for collaborative and reciprocal learning among students, and between students and the teacher, throughout lesson implementation. BDI strategies are not indiscriminate, universalist protocols that purport to work for all students with no reflection or planning required on the part of the teacher for effective delivery. Instead, when properly implemented, they are rigorous, thoughtful courses of action that support teachers as they agentively and purposively elicit student-centered initiative, contributions, discussion, and application, and thereby increase relevance as well (addresses Gay's (2010) dimension \#3).

For example, the U-C-ME strategy of BDI (Herrera, 2016) not only supports the teacher to uncover what is relevant to CLD students, but it does so by progressively revealing what they already know and have learned about the topic/concept, ways in which they learn best, what questions remain, and the extent to which they are ready to monitor their own learning processes and outcomes (addresses Gay's (2010) dimensions \#2 and \#3). The strategy incorporates a graphic organizing tool that is utilized both individually and collaboratively, supporting students to: (a) learn from their peers as well as the teacher; (b) come to realize that many of their challenges are shared; (c) experience opportunities for teacher guidance connected to the heuristic, and (d) benefit from visual knowledge maps and processing, and acting upon new knowledge (addresses Gay's (2010) dimension \#4).

At the same time, use of the U-C-ME strategy, like each of the more than 20 (current) BDI strategies (Herrera, Kavimandan, \& Holmes, 2011; Herrera, Kavimandan, Perez, \& Wessels, 2017), affords the teacher: (a) an intentionally crafted structure through which to collaboratively and actively teach new content; (b) a guide (not a script) for action grounded in best practice for CLD students; (c) a visual through which students can communicate what 
they know, from where they know it, how the topic relates to their lived experiences, the gaps in knowledge that remain, and more; (d) a student personalized tool to which the teacher can refer in facilitating future learning processes, extended learning, addressing gaps in understanding, highlighting the power of collaboration and experiential learning, fostering literacy development, and so forth. Accordingly, the learning that is enabled by such a BDI strategy is efficient (Herrera, Murry, Kavimandan, \& Holmes (in press), yet reciprocal in nature. The student learns about the content and self (addresses Gay's (2010) dimensions \#1, \#4, and \#5). The teacher, inter alia, learns about the student, what engages that student, how he or she learns best (efficiently), his or her heritage influences, and funds of knowledge (social and cultural assets) that he or she brings to learning (addresses Gay's (2010) dimensions \#1, \#2, \#3, and \#4).

The BDI method and its associated strategies, tools, practices, and processes not only target student and teacher relevance as means to learning and knowledge retention, but they also support differentiation of a full lesson, which is divided into predictable phases of teaching and learning. The Activation Phase is focused on the reinvigoration or dynamization of students' prior knowledge, experiences, and learning pertinent to the lesson topic (addresses Gay's (2010) dimensions \#1, \#2, \#3, and \#5). All learners have the opportunity to document their initial connections to the lesson topic, concepts, and/or vocabulary. Students use their home language, their second language, or draw images to name and/or record their ideas - each of which, are frequently underutilized resources in both technocratic and humanistic classrooms. The teacher serves as participant observer, monitoring and documenting these links between prior knowledge and lesson focus, in order to be able to maximize and these connections throughout the remainder of the lesson.

The Connection Phase of the lesson enables the teacher to serve as a facilitator and cultural negotiator who supports students' efforts to navigate the curriculum and construct new meaning from the interactive lesson (addresses Gay's, 2010, dimensions \#2 and \#5). The teacher collaborates with students to confirm or disconfirm initial understandings and predictions, revoices ideas and connections shared by students, systematically employs a variety of grouping structures to prompt autonomous and collaborative learning, and facilitates students in telling their stories or teaching parts of the lesson themselves (addresses, Gay's, 2010, dimensions \#4, \#5, and \#6). Throughout, both content and language, as well as cognitive and metacognitive skills, are developed efficiently -- yet, in caring and asset-building ways.

Finally, the Affirmation Phase of BDI primarily utilizes student-generated products and teacher-developed, formative assessment notes as evidence with which to affirm what students learned, how it was learned, and how it might be applied in the real world of students and their families. In this process, teachers value both student growth and student successes, explicate their relevancy to future learning, celebrate advances in language and content knowledge, and encourage students' reflection on the effectiveness and implications of their thinking and learning processes toward attaining the lesson objectives (addresses Gay's (2010), criteria \#1, \#3, \#4, \#5, and \#6).

Among associated tools and practices of BDI and its maximization of highly differentiated strategies is the student biography card (Herrera, 2016). This heuristic encourages students and families to share their experiential history relevant to learning (sociocultural facet), preferred ways of knowing (cognitive), history with schools and schooling (academic), as well as perceived and demonstrable levels of second language (English) proficiency and/or stage of language acquisition. Consistent with notions of CRTP, this biography card is student-centered, family engaging, culturally relevant, cognitively and 
academically informative, and supportive for linguistically responsive classroom interactions and teaching (addresses Gay's, 2010, dimensions \#2, \#3, \#4, \#5, and \#6). Completion of student biography cards is frequently one of the first activities undertaken by the teacher during the academic year, and the cards are revised throughout the year to reflect current realities and new capacities gained through social constructivist teaching and learning.

Ultimately, BDI is academically rigorous, research-driven, and practically tested as an effective method for CLD and other students (Herrera \& Murry, 2016; McCutcheon, Sponberg, Mena, Murry, \& Herrera, 2018; Murry, 2012; Penner-Williams, Diaz, \& GonzalesWorthen, 2017, 2019). It is situated in the communicative and cognitive approaches of language and content acquisition (Herrera, 2016). At the theoretical level, BDI is grounded in the social constructivist tradition of teaching and learning (Vygotsky, 1978) and the sociolinguistic tradition of language acquisition and literacy development (Van Herk, 2018). BDI has been widely implemented in a diverse range of classrooms, from rural, to suburban, to urban. It has been employed with learners from diverse ethnic and racial backgrounds, including those in schools with predominantly Hispanic and African American student populations. Efforts to document its efficacy for teachers and students are ongoing (e.g., Herrera, Holmes, \& Kavimandan, 2012; Holmes, Kavimandan, \& Herrera, 2018; MacDonald, Miller, Murry, Herrera, \& Spears, 2013; Murry, Herrera, Miller, Fanning, Kavimandan, \& Holmes, 2015; Perez, Holmes, Miller, \& Fanning, 2012). The purpose of the extant study was to address the research question: What are the perspectives (and associated outcomes) of four elementary teachers who implemented BDI in their classrooms?

\section{Theoretical Framework, Part II: Readiness for Increasing Classroom Diversity}

Elsewhere, we have detailed the ways in which teachers' readiness for efficacy in CRTP and other differentiated practices, such as BDI, are effectively captured by a framework known as the accommodation readiness spiral, or ARS (Herrera \& Murry, 2005a, 2005b, 2016; McCutcheon, Sponberg, Mena-Pazmino; Murry, 2012; Murry, \& Herrera, 2018). Accommodation in this sense involves CLD students and their teachers in collaborative endeavors that maximize the resources that each brings to the learning process. It is, therefore, best conceptualized as mutual accommodation (Murry, 2012) and offers a pragmatic sense of teachers' preparedness for and growth toward CRTP in situ.

Grounded in this notion of mutual accommodation, the ARS is, inter alia, a systematic framework for guiding teachers toward and enabling them to self-assess readiness. It is based on over fifteen years of field experience and evolving research with CLD students and their educators (e.g., Herrera \& Murry, 2005b; Herrera \& Murry, 2016; Herrera, Murry, \& Perez, 2008; McCutcheon, Sponberg, Mena, Murry, \& Herrera, 2018; Murry, 2012). This spiral ranges from Level 1, Readiness for Critical Reflection on Practice, to Level 6, Readiness for Application and Advocacy (see Figure 1). Essentially, each of the six levels of the ARS is progressively indicative of a teacher's capacity building for promising practices with CLD students. Because each of these six are, effectively, indicators of readiness for CRTP, they represent, not stages, through which all teachers will proceed, but levels teachers' may attain dependent upon a variety of factors, including: comfort with the profession, teaching circumstances, teacher efficacy, administrative and collegial support, mentorship, and more. The notion of the spiral is immediately illustrative of the sorts of processes involved in progressive capacity building. In part, this is the case because each level above the first has, as its foundation, the levels already attained. Teachers are often supported in their movement up the spiral through teacher education, professional development, book studies, professional

learning communities, or collaboration with a mentor. This framework includes two 
dimensions of teacher readiness: espoused and practical (see Figure 1). Espoused readiness refers to "what the educator says, and may believe, about her or his level of readiness for accommodation" (Herrera \& Murry, 2016, p. 136). This type of readiness can be changed relatively quickly as the teacher gains new understandings and is exposed to new ideas (e.g., through professional development, readings, conferences). By contrast, practical readiness refers to the beliefs and assumptions that actually do guide a teacher's actions, often at a subconscious level (Murry, 2012). Because practical readiness is frequently the manifestation of years of socialization, it can be difficult for an educator to identify or articulate.

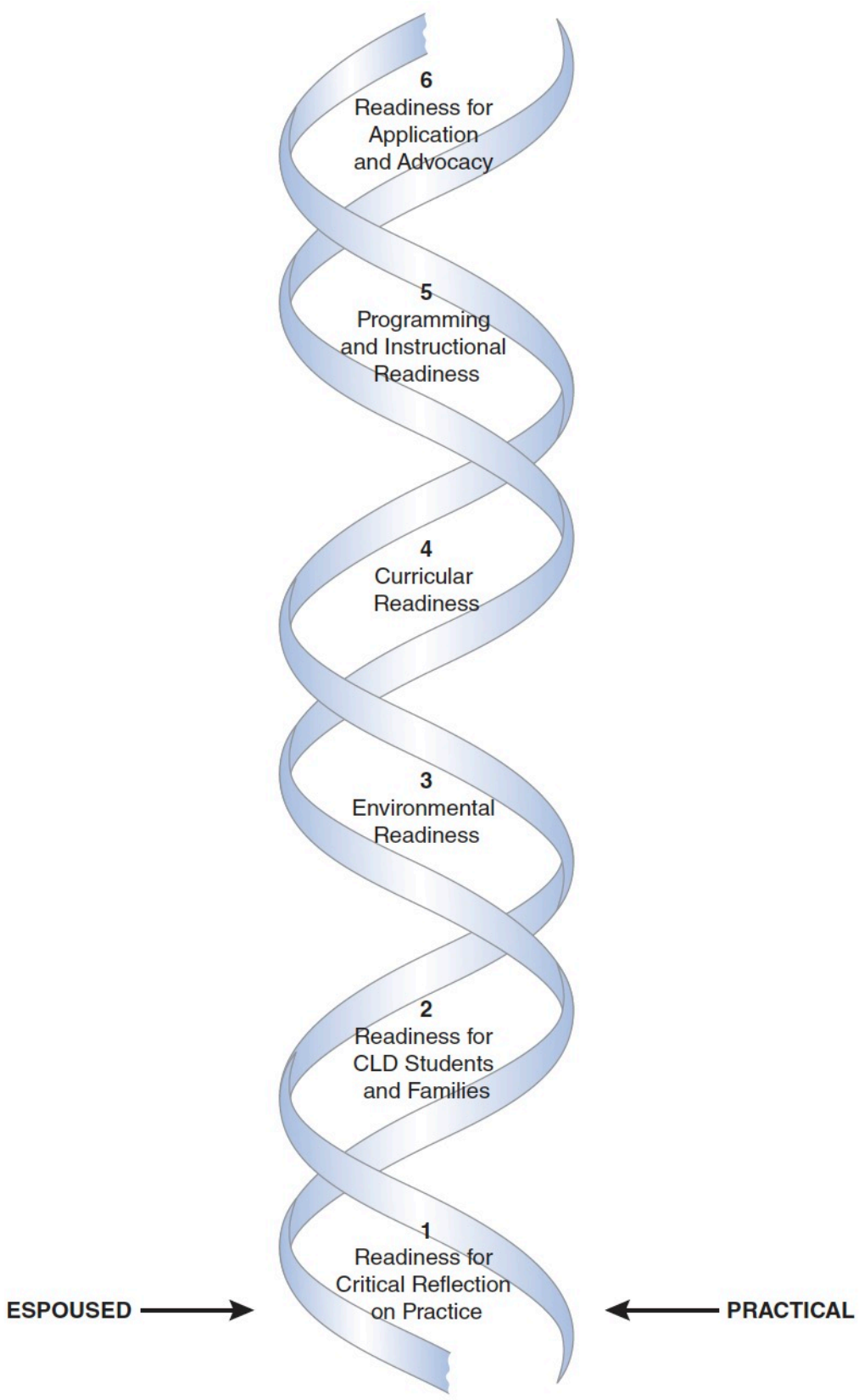

Figure 1. Accommodation Readiness Spiral (ARS). Adapted from Herrera \& Murry (2016, p.135). 
The teacher's periodic regression to a prior level of the ARS is sometimes expected and occasionally unavoidable. Capacity building for effectiveness with CLD students and families is seldom linear, highly predictable, or permanent. This is true because the foundational level of critical reflection on praxis (Level 1) is pivotal to teachers' efficacy with complex and frequently unfamiliar interactions across cultures and languages.

Unlike colloquial notions of teacher reflection (e.g., reflection on lesson outcomes), critical reflection is a much more demanding process (Herrera \& Murry, 2016; Mezirow, 1991; Murry et al., 2015). At its core, this capacity involves locating assumptions in practice and the validity testing of (reflection on) those assumptions about students and families. This aspect of critical reflection acknowledges that White teachers, who are the majority in our schools, frequently have been socialized (e.g., through home, school, and professional life experiences) to certain (often fallacious) assumptions about the capacities, knowledge bases, potential trajectories, and probable educational outcomes associated with students of color, including those who are CLD (Whitaker, Johnson, Hardee, \& McFaden, 2018). Such teachers regularly report that they had not realized that many such assumptions were inaccurate, counterproductive, or hurtful to CLD students and family members (Herrera \& Murry, 2016).

Once the validity of such assumptions has been tested against potentially countervailing evidence (e.g., research), critical reflection further exacts that the teacher endeavor to locate the origin of errant assumptions in his or her prior socialization. Such extended efforts inform teachers about the often-insensible nature of socialization in a particular culture and the potential of it to interfere with teachers' efficacy in teaching CLD students. Over time, recurrent reflection on teaching and critical incidents in practice progressively builds the teacher's capacity to maintain progression up the spiral toward readiness for effective $\mathrm{CRTP}$.

\section{Methodology}

Since the guiding research question for this study was open ended, a qualitative research design was maximized. A qualitative design is appropriate when the outcomes of the study will surround descriptions and interpretations arising from discovery, insight, and analysis (Creswell, 2014). In view of the fact that the research was bounded to a discrete group of teachers, a qualitative case study design was utilized. Lastly, because the research explored teachers' perspectives arising from their experiences with the phenomenon of BDI, the study was approached as phenomenological (Creswell, 2014).

The BDI intervention (phenomenon) was implemented as professional learning, in situ, twice/week for 30 weeks across the school year and featured pertinent theory/research, BDI strategy maximization, and phase-based delivery. Capacity building in BDI especially surrounded teacher agency in contextual and situational adaptations and strategic variations for particular classroom populations vis-à-vis the activation, connection, and affirmation phases of BDI lessons and follow-up/reinforcement activities. Participants were encouraged to view videos of their teaching and reflect upon both classroom dynamics, student responses/participation, and learning outcomes.

\section{Site and Sample}

Two neighborhood schools of an urban, Midwest school district served as the site for this phenomenological case study. Each was indicative of increasingly diverse and complex settings of teaching practice with high numbers of CLD students. At school \#1, roughly 93 percent of students in the school were economically disadvantaged. At the time, 54 percent of students enrolled were African American, 30 percent were Hispanic, 8 percent were White, 
and 8 percent were of another race/ethnicity. Of the total school population, 26 percent of students were emergent bilinguals. Some 20 percent of students had been classified as chronically absent, and 10 percent of students were suspended, at onset.

The demographics of school \#2 were similar. Approximately 82 percent of students were economically disadvantaged. The breakdown of the student population was as follows: 10 percent African American, 66 percent Hispanic, 18 percent White, and six percent other. At this school, 44 percent of enrolled students were emergent bilingual.

The four self-selected teacher participants included one second-grade teacher, two third-grade teachers, and one fourth-grade teacher. All four teachers were female. Two teachers were Latina, and the other two teachers were White. Three of the four were veteran educators.

\section{Data Collection and Analysis}

Semi-structured interviews of participating teachers and participant observation were used to gather data about perspectives on BDI as an instructional method for CLD students, specifics of method implementation, student observable responses to BDI components and strategies, outcomes arising from maximization of BDI strategies, and related topics. Each participant was observed biweekly and was interviewed once during the second term. Observations averaged 60 minutes and interviews 30 minutes in length. Video-recorded interviews were subsequently transcribed.

Initial qualitative coding of collected data was theory-driven and informed by the six levels of the ARS theoretical framework (Herrera \& Murry, 2016; Murry, 2012). Subsequent coding was guided by emergent patterns in participant voice - a process through which themes in participant perspectives were identified. Creswell (2014) describes these efforts as a "process of pulling the data apart and putting them back together in more meaningful ways" (p. 154). According to the ARS framework, the resulting themes were indicative of teachers' espoused readiness for culturally responsive, accommodative practice with CLD students.

To interrogate the practical validity of participating teachers' self-perceptions, we collected video of classroom teaching in each participant's setting of practice. One lesson of each participant was video recorded in the Spring term. We also gathered students' work artifacts and voiced perceptions of the learning process and outcomes. Together, these data allowed us to compare evidence of teachers' practical readiness with what they espoused as their perceived readiness for culturally responsive, biography-driven instruction for CLD and other students.

\section{Findings and Discussion}

Narratives to follow will specify the findings of this phenomenological case study and discuss each of these, especially vis-à-vis the theoretical frameworks for this research -- BDI and the ARS. The first subsection of narrative explores teachers' espoused readiness (an ARS component) to mutually accommodate CLD and other students.

\section{Making Sense of Teacher's Espoused Readiness through the ARS}

Results of this study indicate that teacher perspectives variously aligned with each of the six levels of the ARS. For example, at the most foundational level, Readiness for Critical Reflection on Practice, teachers discussed newly discovered assumptions in their thinking about CLD students. 
I really think that students understand or know concepts in their own ways, but we just don't always as teachers ask them to share that. But once you actually listen to what students have to say ... it makes me think that all of my students are just so brilliant.

As mentioned by this CLD educator, the first step toward maximizing the power of students' knowledge from home, community, and school is creating opportunities for students to talkand for teachers to listen. In a similar vein, another participant explained her shift in thinking about how to respond to student talk in the classroom, and she attributes the transition to new knowledge she has acquired about using the BDI method.

It is amazing just how much they [students] bring, and it's interesting. Before, I would have thought of that as a sidebar conversation like, "Okay, that's not on topic. Let's just stay on the story." But now that I am learning more about this (BDI), it does add to the conversation. I'm like, "Oh! Yeah! That is a good connection." So, I think that's interesting how I've grown as a teacher whereas before, if they were just sharing stories, I would have been like, "Oh, okay, let's keep on topic. This isn't really about that" . . y you know because that's how I learned to teach.

In classrooms such as these, teachers' critical reflection (Level 1 of the ARS) leads to higher levels of responsiveness to students as well as the utilization of their culturally influenced schemas, or frames of references, to support learning. Instead of teachers approaching the curriculum through only the lens of their own socialization and life experiences, these educators have discovered the strength of building from students' background knowledge to increase the relevance of their instruction.

Level 2 of the ARS is Readiness for CLD Students and Families. As teachers actively make critical reflection part of their daily mode of operation, they become increasingly prepared to serve their CLD students and families effectively. One teacher descriptively recounted the impact that BDI had on the depth of her students' understandings.

I was laughing at [parent-teacher] conferences this year, how many kids were talking to their parents and saying, you know, "Here we learned about Susan B. Anthony" and "Let me tell you... and this is why it's important." So, I mean, I'm noticing that it's [learning], it's deeper. . . . It's like the roots are now starting to sprout. If that makes sense. [Interviewer: And so, where would the roots come from?) I think in them (the students].

This example illustrates the teacher's increased effectiveness with students. Moreover, the teacher attributes the root of the learning to the students themselves. Recognizing and building upon the assets that learners bring is at the core of this level of readiness for differentiated practice and BDI. Another participant likewise acknowledged that each student has something valuable to contribute to the learning processes in her classroom.

But some of the kids that were our shyest kids, were sharing and talking, and they did not do that at the beginning. But I feel like they just feel more confident and you know the whole theory behind BDI is that they have something to share... every kid. 
When teachers view students from an asset (rather than a deficit) perspective, the classroom ecology begins to shift. Learners see themselves recognized for what they do know, and they become more confident to take risks, knowing that what they have to say will be respected and used to move learning forward.

Level 3 of the ARS, Environmental Readiness, relates to educators' capacities to maximize internal and external environments for learning. One teacher discussed the effect that using BDI strategies had on the learning community, as students used the tools to become more active, autonomous learners.

I say it [student efficacy and risk-taking] just starts from the beginning and setting up that environment like that when we use those strategies. . . We start at the beginning [of the year] and ... it's just consistency. The strategy of BDI lets students know that it's okay to make a mistake. That's what I think . . . the biggest thing was when we were doing the um . . is it the quilt [Vocabulary Quilt - a BDI strategy]? And they're allowed to write any word that they want ... that comes to their mind ... when they think of that word. And it doesn't matter if it's right or wrong because at some point during their learning, they're going to figure out it's wrong and they can cross it out and they can put the right word there.

Sometimes teachers short-circuit their own efforts to implement culturally responsive praxis because they operate from the faulty belief that allowing learners to document and share their initial thoughts about a topic or word will then imprint potentially incorrect ideas in their minds. This excerpt highlights the teacher's awareness of the need to allow students to discover and experience learning for themselves.

BDI and its related strategies enable students to use everything in their environment - their own knowledge, the curriculum, and their interactions with peers- to negotiate meaning and construct new understandings. Doing so allows each student to enter the learning process from her/his own starting point. Another participating teacher explained how BDI tools help make this teaching/learning dynamic possible:

I mean, just the tool helps. They have that in front of them ... Some had very, very detailed [information] and were really tracking, and some were not quite as on track but at least they had some of the similar ideas and they could share. So, I think that was a scaffold in and of itself. The ones that can soar higher -they have the chance to do that. And the ones that, you know, might be still behind, they at least have something to add.

With the flexibility that BDI tools provide teachers for differentiation, all students, regardless of exceptionality, language proficiency, or academic level, are able to engage in the task at hand and use the same tool to support their learning.

Curricular Readiness, Level 4 of the ARS, targets the curriculum essentials (e.g., standards, adopted curriculum, student access) that are necessary for students' achievement and success. Participating teachers frequently discussed the caliber of learning that was possible when they employed the BDI method. A third-grade teacher's discourse is indicative. 
You know, when I think about academic success, I think of, they're [students are] gonna go into fourth grade as learners. They're gonna go into fourth grade confident. They're gonna go into fourth grade saying, "Oh, I am a researcher," you know, "I can look at this difficult text and unpack it"-which we always say, "Have you unpacked the text? —um, pull out that information and turn around and teach it. And I think, ultimately, you know, if we're looking at college and career ready, that's what we want our students to do.

Teachers, including this participant, required their students to be thinkers, not just receivers. Time in the classroom wasn't wasted. For their own benefit as well as that of their peers, students had to be truly involved in learning. This teacher's practices related to homework outside the classroom and reflected the epitome of what we would hope for in a teacher's curricular readiness for CLD students. For her, it was important that students' families also were able to engage at some level with the curriculum. She relayed:

We've also changed the way that we do our homework in third grade. So, you know, we do have some practice worksheets but we've also embedded conversation starters. So, like this week, we just did a lesson on healthy eating. One of the homework pieces is to, um, you know ... prepare a meal with your family. See how you can add in some extra vegetables, or fruit, and then come back and share it with the class. Um, and I think our parents really do appreciate that because, you know, that's not something that they have to overthink.

Finding innovative ways to involve parents in their child's learning further communicates to students that their culturally influenced ways of knowing and interacting in the world matter. It also supports the teacher's ability to bridge between home and school and allows students to see the applicability of their learning beyond the classroom.

Level 5 of the ARS, Programming and Instructional Readiness, was also evident in the teacher interview data. One teacher explicitly connected the three phases of BDI to higher levels of student engagement and lower incidences of problematic behavior.

I think back to last year and maybe not having so much of those structures that BDI has in place like the Activate, Connect and Affirm, you know, all throughout the lesson. And I think because we're doing that all throughout the lesson, students are either actively engaged with partners or they're actively engaged on their own or they're ... engaged in our class discussion. We're going in and out of that. Because we've had that flow with the lesson, it's really helped to lower [off-task] behaviors, overall ... in the classroom. Just because they're excited, I guess ... to share, and then they're just always kept on their toes ... asked to think and produce, and that's really been beneficial.

Because BDI heavily emphasizes the importance of students collaborating to support and learn from one another, teachers who implement the method fluidly use grouping structures, such as partners and small teams, throughout the lesson. Students are able to bring their whole selves (their knowledge, talents, skills, ideas, emotions, etc.) into the learning process, and they are continually expected and supported to build, negotiate, challenge, confirm, 
provide evidence, summarize, and so forth. BDI classrooms, therefore, maintain steady engagement of students throughout the lesson cycle. One teacher described the level of thought that she puts into decisions about which students to group together.

A lot goes into that mental process of configuring heterogenous groups I'm going to tell you. Like, because even sometimes I get nervous when I'm thinking about a group because I'm like, "Oh, those two behaviors, I don't know," but academically, it's beneficial for that student. And so, sometimes you have to take risks, and sometimes after two days I might go, "No, uh-huh, you move over here and you move here." And, um, but again, it's knowing my kids.

The readiness of this teacher for instructing CLD students is apparent in both her willingness to take risks in order to leverage student assets, and in her preparedness to make situational changes (i.e., re-configuring student groups, as needed) as the learning process progresses.

At the upper range of the spiral is Level 6, Readiness for Application and Advocacy. The words of one teacher highlight her readiness to apply knowledge of culturally responsive instruction with CLD students.

I have been a teacher for, this is my sixth year, and this is the first year where building that community has been so much easier than in the past. And I do believe that it is because of the Biography-Driven Instruction tools that I use in the classroom. And we're communicating, and we're talking, and we're sharing all the time. It's not one day a week. It's every day.

This teacher, as well as the other three participants, described the consistency with which they maximized BDI strategies and the associated tools for students' documentation of learning. When asked how she would respond to someone who might question the amount of work required on the part of the teacher to implement BDI, one second-grade teacher answered:

It's not that much work! I mean, it takes a little bit of planning, um, but you know a lot of it is on the spot. You gotta work with your kids. I mean, it was, you know, listening to be engaged with them.

From the perspective of the participants, it's the intentionality of the teacher to provide opportunities for students to share, to listen to what they say, and to then use those insights to orchestrate instruction that makes BDI work. Further, when BDI works, emergent bilingual and other students are engaged and stretched to their zones of proximal development (Vygotsky, 1978) -- not only by the teacher, but also by their peers (especially those who are more capable ).

\section{Documenting Evidence of Practical Readiness through Classroom Observations}

It is one thing to espouse that certain methods, strategies, and practices guide your teaching, or that high levels of engagement characterize the students in your classroom. It is another for observers to come to the same conclusions based on observations of your praxis in action. Although each level of readiness for CLD students was evinced in the teacher interview data, the researchers also explored the alignment of observed classroom practices 
with the ARS. Figure 2 summarizes typical examples of teaching and learning dynamics from the observed lessons of the four participating teachers that align with the ARS level.

\begin{tabular}{|c|c|c|c|}
\hline $\begin{array}{c}\text { ARS } \\
\text { Level }\end{array}$ & Descriptor & $\begin{array}{c}\text { From Teacher Voice: An Example of Observed Teaching } \\
\text { \& Learning Dynamics Arising from BDI }\end{array}$ & $\begin{array}{l}\text { Grade } \\
\text { Level }\end{array}$ \\
\hline 1 & $\begin{array}{l}\text { Readiness for } \\
\text { Critical } \\
\text { Reflection on } \\
\text { Practice }\end{array}$ & $\begin{array}{l}\text { After students had a chance to individually record personal } \\
\text { connections to the topic (Red Cross) and discuss them with } \\
\text { partners, they gathered as a whole group to share ideas while } \\
\text { the teacher documented them on a class chart. The teacher } \\
\text { poses a question about why the symbol of the organization had } \\
\text { been chosen. Students explain their ideas about the symbol and } \\
\text { their connections to the topic. }\end{array}$ & 3 \\
\hline 2 & $\begin{array}{l}\text { Readiness for } \\
\text { CLD Students } \\
\& \text { Families }\end{array}$ & $\begin{array}{l}\text { In listening to students discuss main ideas from the text } \\
\text { passage with partners, the teacher identifies that many students } \\
\text { do not know the meaning of the word apartment. Through her } \\
\text { subsequent instructional conversation, the teacher uses the } \\
\text { lived experiences of students to explain the concept. She then } \\
\text { expands upon the meaning of the word by linking it back to the } \\
\text { text and gathering students' text-based connections. }\end{array}$ & 2 \\
\hline 3 & $\begin{array}{l}\text { Environmental } \\
\text { Readiness }\end{array}$ & $\begin{array}{l}\text { Students hold discussions as they collaborate in a small group } \\
\text { to explore math concepts related to fractions. They use the } \\
\text { learning tools to demonstrate their individual levels of } \\
\text { understanding and come to consensus. }\end{array}$ & 4 \\
\hline 4 & $\begin{array}{l}\text { Curricular } \\
\text { Readiness }\end{array}$ & $\begin{array}{l}\text { When the class has finished reading the text and discussing the } \\
\text { vocabulary words, students return to the Vocabulary Quilts. } \\
\text { The quilts contain the students' initial thoughts and predictions } \\
\text { about each of the vocabulary words. In small groups, students } \\
\text { work together to confirm/disconfirm their initial associations } \\
\text { and add new curricular understandings. }\end{array}$ & 3 \\
\hline 5 & $\begin{array}{l}\text { Programming } \\
\& \text { Instructional } \\
\text { Readiness }\end{array}$ & $\begin{array}{l}\text { After the class finishes reading a passage of text together, the } \\
\text { teacher asks students to think about and discuss connections } \\
\text { they can make to what they read. The teacher engages in an } \\
\text { instructional conversation with a small group about the word } \\
\text { marketing to support their sharing of ideas. She then brings the } \\
\text { class back together and encourages learners to share their ideas } \\
\text { with the whole group. She also revoices some of the } \\
\text { connections to "marketing" previously made by the small } \\
\text { group. }\end{array}$ & 3 \\
\hline 6 & $\begin{array}{l}\text { Readiness for } \\
\text { Application \& } \\
\text { Advocacy }\end{array}$ & $\begin{array}{l}\text { The teacher releases students to work in groups with the text } \\
\text { and their DOTS charts. Students identify words from the text } \\
\text { that reflect key ideas about the life of the first African American } \\
\text { patent holder. Students document these words on their } \\
\text { individual charts and prepare to share ideas with the class for } \\
\text { recording on the class chart. The teacher circulates to listen to } \\
\text { the ideas at each group and prompt further thinking. }\end{array}$ & 2 \\
\hline
\end{tabular}

Figure 2. Observed Evidence of Teachers' Practical Readiness for the six ARS Levels. 


\section{Themes in Teacher Perceptions of BDI Processes and Outcomes}

The results of direct interpretation of teacher interview data further revealed the following five themes in participants' perceptions of BDI processes and outcomes:

1. Building relationships leads to a positive learning climate.

2. Using strategies promotes student engagement.

3. Scaffolding gives access to all learners.

4. Focusing on relevance supports academic conversations.

5. Allowing students to be teachers enables them to achieve rigor.

Each of these themes was indicative of participants' espoused levels of readiness to effectively meet the needs of CLD students in their classroom teaching. These themes are explored individually in the subsections that follow. The subheading for each introduces both the researchers', etic interpretation (nonitalicized, theme title) and a pertinent excerpt of indicative and emic, participant discourse (italicized passage of teacher voice).

Building relationships leads to a positive learning climate-It's about taking this journey together as learners. This first theme related to changes teachers witnessed in their classroom environments as a result of their efforts to build relationships with and among students. Philosophically, relationship-building lies at the heart of BDI (Herrera, 2016). One participating teacher explained:

I just think back to last year and how my students really struggled with collaborating. The climate... I felt like they were mean to each other, I guess. But with BDI, just because that was set up from the beginning, you know ... like I see students honoring each other's opinions and bouncing ideas off one another. And they feel really comfortable like sharing and bringing to the table what they know and then expanding on that. I feel like it's just changed the climate of our classroom for the better.

When teachers value students' perspectives and use their ideas as a springboard for learning, they model what it means to learn and interact as equal members of a collaborative learning community. The fourth-grade teacher explained how this kind of valuing and supporting one another differed from the previous norms in her classroom.

Before this year, a lot of math was independent. We teach. We model. ... I do. We do. You do - and the you do is you do. We're not, you're not copying off of anybody, right? You're not cheating. You're not like..." And it was a lot of like kids doing work and being like, "Don't look at my work." You know? And this year I have not had one ... that is, nobody says, "Don't look at my work." Nobody says, "You're cheating. You're copying.” No. It's all, "Oh, here, let me help you” or "Oh, this is what's going wrong” or it's, you know, it's that conversational piece... And so, it's that understanding that we're all in this together. . . And it's just all about building that community in your classroom.

As teachers came to know their students better and fostered positive relationships among students, they were also better prepared to facilitate the flow of reciprocal teaching and learning that characterizes BDI. 
Using Strategies Promotes Student Engagement-They were engaged... they're having fun. The second theme spoke to participants' shared perspective that their use of BDI strategies supported student engagement throughout the lesson. One secondgrade teacher compared her past instructional practices to those that she currently implements using BDI. She shared:

I think the biggest thing is I've grown professionally in my involvement of the students. I know I keep saying that, but BDI for me is really honing in on all the kids being engaged and excited about learning. . . . Like, in order for the kids to be engaged, I had to be engaged with them, you know, listening to them. And, so, I think it's [my ability to weave student talk into instructional conversations] that has grown with these strategies.

In this excerpt, the participant mentioned the need to first listen to students in order to more actively engage them in learning. Herrera (2016) refers to this teacher's role as "participant observer" (p. 75). The BDI strategies are designed for students to use the same tools to document their learning throughout the lesson. As such, the tools fuel classroom conversations, which in turn feed the teacher's ability to weave student thought and talk together with the lesson's content. This process allows teachers to jointly produce with the class.

Another teacher shared how the practice of consistently allowing learners to engage from wherever they are in their thinking enables all students to participate and share, without having to fear what might happen if they are wrong.

At this point, we're at the end of the year. All year they've [students have worked on writing things, whatever they thought, taking those risks, and being okay with, "And you know what? If I get this wrong, when I rotate that paper, that partner over there, they're probably gonna fix it for me and then I'll know my mistake." And so, it just . . . it gives that tool for students to use that says, "Hey, it's okay if I don't know." Somebody else might know ... And it's just using that constantly.

The collaborative peer interactions that BDI strategies and tools promote also serve to support students' development of a positive cognitive belief system regarding themselves as learners. With increased levels of student engagement and risk-taking come increased levels of student confidence. Teachers found that such classroom dynamics also gave them renewed energy for their own teaching.

Scaffolding gives access to all learners- It allows for me to meet my learners where they're at. This third theme reflected the various ways in which scaffolding was perceived to be built into the tools as well as the teaching and learning dynamics of BDI. The following excerpt exemplifies this theme.

The BDI strategies are the tool[s] that lead to more rigorous conversations that lead to more rigorous work. And so, what can start off as a very . . . just basic knowledge, I can then move up, and up, and up because they have a tool that allows them to apply it [the conceptual knowledge] at a higher level of thinking.... They're able to do these things because of conversations, and peer 
support, and teacher support, and tools that have allowed them to feel successful in math for probably the first time ever.

This teacher attested to the importance of strategy-based tools. In addition, she highlighted the contributions of the teacher, the importance of instructional conversations, and the support of student peers, as they scaffold learning for one another (Murry, 2012).

One participant discussed a particular student's learning progress to illustrate the specific kinds of effects BDI strategies had in her classroom. The notion of a tool in the hand was particularly valuable.

One of my students who just struggled . . . academically, for a long time. He actually is an English language learner, and he recently qualified for special education services. So, all year he's been struggling with reading and even opening up in class and sharing. I think it's been amazing watching him grow. And looking at him, and seeing him turning and discussing. . . . Like we were talking about career choices and ... we were using Vocabulary Quilts and some of that, and him then sharing what he wants to be. And him being able to generate -- because he had that tool in his hand . . . to generate a whole sentence about that, without using a sentence starter or anything, but just on his own, just because he has those tools, was just like amazing!

This teacher witnessed, first hand, how learners at every level of ability and readiness were able to truly engage with the classroom learning tasks. Furthermore, students were able to use the tools to take responsibility for their own learning, with fewer structured teacher supports. By scaffolding the success of every student, the entire learning community is able to benefit from the wealth of ideas, experiences, and talents that each member contributes.

Focusing on relevance supports academic conversations-You could see how many words they were using with those connections. The fourth theme in participating teachers' discourse highlighted their view that allowing students to make culturally relevant connections supports their academic discourse. CLD students bring value-added connections to learning in the entire, classroom community. Because students are encouraged to link their background knowledge from home, community, and school, BDI lessons provide abundant opportunities for them to discuss personal connections to the curriculum. A third-grade teacher discussed how this focus leads to higher levels of language production.

I've seen my students having more academic conversations. Really thinking about the text in different ways, and trying to . . . with other things, too, outside of ELA. They're just always wanting to make connections . . . So, it [BDI] has really increased that language and having those academic conversations where they're actually using the vocabulary and they really understand.

As evident in this excerpt, students' desires to make connections to the content via BDI strategies occurred across differing subject areas. Their academic conversations were catalysts for, as well as products of, the vocabulary development taking place. Key to the emergence of cogent, academic conversations were the recurrent opportunities that teachers provided for students to share their connections to lived experiences. 
One teacher discussed the importance of digging deeper into what she previously might have considered sidebar conversations, "It makes it valid. It makes their experiences, their thinking, valid. And with that validity, I think they're able to say, 'Oh, okay! This is important to me." The teacher revisited this idea when discussing how BDI has served as an equalizer in her classroom, allowing every student to be equally valued. "I think it really does circle back to how they feel that their thoughts are suddenly important. So, with that support, um, they're more eager to share, you know . . . no matter what their background is." Encouraging students to share their connections and then bringing them into the third space of the classroom (Gutiérrez, Baquedano-López, \& Tejeda, 2003) allowed students' assets to be viewed and used as building blocks for constructing curricular knowledge. These actions on the part of the teacher communicated to students the value of their experiences, which led to an increase in the number of students engaged in conversations and in the depth of the conversations taking place amidst challenging activities.

Allowing students to be teachers enables them to achieve rigor-Then they're able to take that ... and kind of build from each other. This fifth, emic theme typified participants' shared belief in the importance of encouraging students to take ownership of their learning. When students became leaders and teachers for their peers, they reached higher levels of academic rigor. The third-grade teacher relayed:

When they [students] feel confident enough that "I am the learner," you know, and "I can teach others," then you get that rigor because they're having to restate it [what they learned] to each other. They're having to write it. They're having to read it, you know. They're having to put it in a final product. So, it just becomes stronger.

The individual accountability emphasized throughout the lesson, and especially in the affirmation phase of BDI, led students to more thoroughly internalize their learning.

Teacher comments also reflected the way BDI allowed them to support students' holistic development, while simultaneously moving all learners closer to the academic goals of the lesson. One participant described a particular student in her classroom community, whose collaborations with peers had far-reaching effects.

He comes from a very, very rough home life. Umm and he's had some behavior issues. I mean, when I got the card that said he was in my class I was kinda like "uuhhh.” I mean like, always talking, just kind of a problem student. But, you know, he's never been a problem for me ... and the two girls he's with [in his small group] struggle a little bit academically too . . . but math really is a struggle for them. And so, I feel the reason why they're not a problem this year is the strategies are giving them opportunities to talk, and be leaders. And now, he's the child that he can get done with the math page in two minutes... Yes, he's gonna be a problem if the teacher doesn't have strategies in place. . . But, BDI has allowed him to kind of take that leadership role and . . . so he wants - he's gonna be a teacher. Well,. I told him ... he's a natural.

This teacher saw the assets of this child and used BDI to provide opportunities that allowed him to succeed. Although he had previously been perceived as a challenge, through BDI, he excelled, as a student, and as a leader. Not only did he further his own learning through his 
efforts to help others, but he also demonstrated the true caliber of his character by selflessly reaching out to rally the efforts of his peers so they, too, could achieve success.

\section{Conclusion}

Together, the findings of this phenomenological, case study recurrently indicate that BDI holds the potential to support teachers' enactment of culturally responsive teaching with CLD and other students. Teachers' voices, captured especially through semi-structured interviews provided evidence of their espoused readiness for accommodative, CRTP. Instructional processes and student outcomes germane to BDI implementation in the participating teachers' elementary classrooms, were summarized across the five themes from the study. Variously, these themes typified teachers' efforts to: target relevance, foster social constructivist relationships, maximize student assets through BDI strategies, scaffold risktaking, and even enable students to be teachers. The themes also reflected classroom outcomes, such as: a positive learning climate, engagement, access to the curriculum, academic conversations, and rigor for students.

Classroom observations provided corroborating evidence of participants' practical readiness as well. BDI instructional practices that teachers discussed in their interview excerpts featured here were also evident in their classroom teaching. Like their vernacular, their actions in CRTP reflected the many ways in which BDI served as an effective vehicle for teachers' translations of theory into promising practice in highly diverse classrooms.

The results of this study also illustrate the merit of the ARS (Herrera \& Murry, 2016) as a theoretical framework for exploring the preparedness of teachers to serve CLD students in mutually accommodative ways. Beyond the distinction between espoused and practical readiness, the ARS also provides educators with a frame for their descriptive analyses of actions (and types of readiness for action) in situ that are normatively characteristic of effective pedagogy for diverse classroom contexts.

As a heuristic for professional development and/or teacher preparation, the ARS provides a visual guide to either candidate or practitioner readiness and growth toward CRTP. When used as a self-monitoring or assessment tool, the ARS can support each in determining why he/she may be struggling to achieve desired results in the appropriate differentiation of praxis. Level 1 prompts such educators to engage in an additional layer of critical reflection on whether their assumptions (especially those that are technocratically or social constructivist grounded) about their readiness or their praxis conflict with or reinforce normative guidelines for more promising practices in highly-diverse, schools and classrooms.

Accordingly, the findings of this case study offer a foundation for future research on CRTP and teacher education for instructional differentiation, featuring BDI as method and or the ARS as a guide to readiness for diverse classrooms. These findings suggest that future research explore, inter alia: BDI impacts on student achievement, BDI as a promising method for candidates' forays into CRTP with CLD students, and a broader examination of the ARS as a useful framework for educators' self-assessments and monitoring of capacity building and readiness for effectiveness in diverse and complex educational settings. 


\section{References}

Crego-Emley, A., \& Treuhaft-Ali, L. (2017). Thinking beyond the deficit model: Culturally relevant pedagogy and the achievement gap (Yale Education Studies). http://debsedstudies.org/thinking-beyond-the-deficit-model/

Creswell, J. W. (2014). Research design: Qualitative, quantitative, and mixed methods approaches (4th ed.). Sage.

Gay, G. (2010). Culturally responsive teaching: Theory, research, and practice (2nd ed.). Teachers College.

Gorski, P. (2014). Imagining an equity pedagogy for students in poverty. In P. Gorski \& J. Landsman (Eds.), The poverty and education reader: A call for equity in many voices (pp. 213). Stylus.

Gutiérrez, K. D., Baquedano-López, P., \& Tejeda, C. (2003). Rethinking diversity: Hybridity and hybrid language practices in the third space. In S. Goodman, T. Lillis, J. Maybin, \& N. Mercer (Eds.), Language, literacy, and education: A reader (pp. 171-187). Open University.

Hammond, Z. (2015). Culturally responsive teaching and the brain: Promoting authentic engagement and rigor among CLD students. Corwin.

Herrera, S. (2010). Biography-driven culturally responsive teaching. Teachers College.

Herrera, S. (2016). Biography-driven culturally responsive teaching (2nd ed). Teachers College.

Herrera, S., Holmes, M., \& Kavimandan, S. (2012). Bringing theory to life: Strategies that make culturally responsive pedagogy a reality in diverse secondary classrooms. International Journal of Multicultural Education, 14(3), 1-19.

Herrera, S. G., Kavimandan, S. K., \& Holmes, M. A. (2011). Crossing the vocabulary bridge: Differentiated strategies for diverse secondary classrooms. Teachers College.

Herrera, S. G., Kavimandan, S. K., Perez, D. R., \& Wessels, S. (2017). Accelerating literacy for diverse learners: Classroom strategies that integrate social/emotional engagement and academic achievement, $K-8$ (2nd ed). Teachers College.

Herrera, S., \& Murry, K. G. (2005a). Mastering ESL and bilingual methods: Differentiated instruction for culturally and linguistically diverse (CLD) students. Pearson.

Herrera, S., \& Murry, K. G. (2005b, April). Readiness for accommodation? Teachers and their CLD students. A paper presented at the annual meeting of the American Educational Research Association (AERA).

Herrera, S., \& Murry, K. G. (2016). Mastering ESL/EFL methods: Differentiated instruction for culturally and linguistically diverse (CLD) students (3rd ed.). Pearson.

Herrera, S., Murry, K., \& Kavimandan, \& Holmes, M. (in press). The trajectory of the invisible teacher: Latinx teachers in search of professional belonging. In C. D. Gist \& T. J. Bristol (Eds.), Handbook of research on teachers of color. AERA.

Herrera, S. G., Murry, K. G., \& Perez, D. R. (2008). CLASSIC: Transforming hearts and minds. In M. E. Brisk (Ed.), Language, culture, and community in teacher education (pp. 149-173). Lawrence Erlbaum.

Holmes, M., Kavimandan, S., \& Herrera, S. (2018). Reaching rigor for English learners through responsive interactions of care. In N. Guler (Ed.), Optimizing elementary education for English language learners (pp. 91-115). IGI Global.

Keefer, N. (2017). The presence of deficit thinking among social studies educators. Journal of Social Studies Education Research, 8(3), 50-75. 
Lew, M., \& Nelson, R. (2016). New teachers' challenges: How culturally responsive teaching, classroom management, \& assessment literacy are intertwined. Multicultural Education, 23(3), 7-13.

McCutcheon, S., Sponberg, E., Mena. P. J., Murry, K., \& Herrera, S. (2018). Case study of the accommodation readiness spiral as an evaluative framework for action research plans. Prairie Journal of Educational Research, 2(1), 18-32.

MacDonald, G. L., Miller, S., Murry, K., Herrera, S., \& Spears, J. D. (2013). Efficacy of ACA strategies in biography-driven science teaching: An investigation. Cultural Studies in Science Education, 8(4), 889-903. http://doi.org/10.1007/s 1 1422-013-9517-4

Mehta J. (2013). The penetration of technocratic logic into the educational field: Rationalizing schooling from the progressives to the present. Teachers College Record, 115(5), 1-36.

Mezirow, J. (1991). Transformative dimensions of adult learning. Jossey-Bass.

Morrison, K., Robbins, H., \& Rose, D. (2008). Operationalizing culturally relevant pedagogy: A synthesis of classroom-based research. Equity and Excellence in Education, 41, 433-452. http://doi.org/10.1080/10665680802400006

Murry, K. (2012). Cognitive development, global learning, and academic progress: Promoting teacher readiness for CLD students and families. Journal of Curriculum and Instruction, 6(1), 11-24.

Murry, K., \& Herrera, S. (2018, May 11-12). Do I matter? Increasing relevance and engagement in diverse classrooms. Paper presented at the South States TESOL Conference, Orlando, FL.

Murry, K. G., Herrera, S. G., Miller, S. S., Fanning, C. A., Kavimandan, S. K., \& Holmes, M. A. (2015). Effect of transnational standards on U.S. teacher education. Forum for International Research in Education, 1(3), 41-63.

National Center for Education Statistics (NCES). (2016). The condition of education 2016. U.S. Department of Education.

National Center for Education Statistics (NCES). (2017). The condition of education 2017. U.S. Department of Education.

Penner-Williams, J., Diaz, E. I., \& Gonzales-Worthen, D. (2017). PLCs: Key PD component in learning transfer for teachers of English learners. Teaching and Teacher Education 65, $215-229$

Penner-Williams, J., Diaz, E. I., \& Gonzales-Worthen, D. (2019). Sustainability of teacher growth from professional development interculturally and linguistically responsive instructional practices. Teaching and Teacher Education, 86, 1-13.

Perez, D., Holmes, M., Miller, S., \& Fanning, C. (2012). Biography-driven strategies as the great equalizer: Universal conditions that promote K-12 culturally responsive teaching. Journal of Curriculum and Instruction, 6(1), 25-42.

Van Herk, G. (2018). What is sociolinguistics? (2nd ed.). Linguistics in the World Series. John Wiley \& Sons.

Vázquez-Montilla, E., Just, M., \& Triscari, R. (2014). Teachers' dispositions and beliefs about cultural and linguistic diversity. Universal Journal of Educational Research, 2(8), 577-587. http://doi.org/10.13189/ujer.2014022806

Vygotsky, L. S. (1978). Mind in society: The development of higher psychological processes. Harvard University. 
Whitaker, W., Johnson, L. C., Hardee, S. C., \& McFaden, K. L. (2018). The southern mind and the savage ideal: Deconstructing identities of place in the cracker state. Teaching Education,29(4), 407-420. https://doi.org/10.1080/10476210.2018.1513999

Young, E. (2010). Challenges to actualizing culturally relevant pedagoegy: How viable is the theory in classroom practice? Journal of Teacher Education, 61(3), 248-260. https://doi.org/10.1177/0022487109359775

\section{About the Authors}

Kevin Murry is Professor of Curriculum and Instruction (CEII) in the College of Education at Kansas State University and Director of Research and Development for the Center for Intercultural and Multilingual Advocacy (CIMA). His scholarship has emphasized the professional development of K-16 teachers for the assets of culturally and linguistically diverse (CLD) students. His recent research has underscored teacher readiness for highly differentiated, culturally responsive teaching, the phenomenology of BDI, and the epistemologies of identity-driven, cross-cultural interactions in schools. In addition to his textbooks, he has contributed recent articles to the Forum for International Research in Education, the forthcoming AERA Handbook of Research on Teachers of Color, and the Journal of Teaching and Learning. Dr. Murry has also developed curricula for, and conducted professional learning courses and seminars with, teachers and school leaders from a range of international settings, including Mexico, Ecuador.

Melissa Holmes is as Assistant Director for CIMA at Kansas State University. Her post-secondary teaching experience focuses on the academic literacy development of emergent bilinguals in higher education, and her research emphasizes biography-driven instruction in K-16 settings. In addition to supporting Kansas teachers to meet the needs of all learners, she has been devoted to collaborating with teachers from Ecuador, Mexico, and Saudi Arabia to explore new ways of engaging students and fostering English acquisition. Ms. Holmes has presented at international, national, and regional conferences on the differential learning needs of culturally and linguistically diverse (CLD) students, effective recruitment and retention strategies for teachers of color, and the preparation of preservice and inservice educators to be responsive teachers and advocates for CLD students and families. She has co-authored a book and several articles related to the language development of CLD students.

Shabina Kavimandan is a Title III, Project Manager for CIMA and the College of Education and offices at K-State's, Olathe campus. Her teaching, coaching and professional learning for practicing $\mathrm{KCMO}$-area teachers emphasizes the differentiation of teaching practices for literacy development, academic learning, and student retention. Shabina has authored or coauthored proposals for, led instruction in conjunction with, researched the outcomes of, and written summative reports that document the outcomes of external funding projects for teacher learning pertinent to culturally responsive teaching praxis (CRTP). A CLD parent herself, Shabina brings unique insights to schools and teachers who are transitioning to culturally relevant practices and the enhancement of parental engagement. To date, she has coauthored three texts and six articles in refereed journals on teaching and teacher education, including a recent one for the Teacher Education Quarterly. 